\title{
PSYCHE.
}

\section{A NEW STRUCTURAL CHARACTER IN INSECTS.}

\author{
BY R. A. COOLEY B. S., AMHERST, MASS.
}

While studying the wings of the Gypsy Moth for androconia I observed a peculiar structure which I have never seen definitely described. This structure is a small oval patch of short, sharp spines on the under side of the fore wing, near the base of the hind margin. A short notice of this, with illustrations, appears in Part II of Prof. C. H. Fernald's Report on the Gypsy Moth, just published. The spiny area was also found in Crambus laqueatellus Clem., and is described in Prof. Fernald's Monograph of the Crambidae, recently published in the Thirty-third Annual Report of the Massachusetts Agricultural College. Further investigation has revealed the fact that the structure is not confined to Porthetria dispar (Linn.), and Crambus laqueatellus Clem., but is present in very many of the Heterocera, and that whenever this occurs, there is always a corresponding patch on the thorax, at the place where the spines rest when the wings are in repose.

The only previous mention of anything of the kind, so far as known to me, is by Dr. W. Donitz, who in an article entitled "A Singing Lepidopteron," published in $\mathrm{r} 887$ in the Berliner entomologische Zeitschrift, Vol. 3I, states that while holding a male of Dionychopus niveus Men. between his fingers it made a chirping noise. $D$. niveus is found in Japan and Siberia and is related to our Spilosoma. $\mathrm{He}$ states that the sound is produced by the rubbing together of brushes of sharp chitinized spines, one on the under side of the fore wings near the base, and one on the upper side of the hind wing. $\mathrm{He}$ expressed the opinion that the sound is produced for sexual attraction, but he was hardly justifled in this conclusion since he had only males for examination. Though I have studied many species I have never found anything like what Dr. Donitz describes on the hind wing, but as previously stated, the second area is always found on the thorax. May it not be that he was mistaken in his observations?

The following descriptions were made from Catocala concumbens Walk., an insect which shows the structures distinctly, and which may be considered as typical. Figs. I, 2, 3, and 4 of Plate 9, were drawn from this insect. On the fore wing the area Fig. I, s, is more or less oval in form with its longest axis nearly parallel to the hind margin of the wing and it is without scales. It has a definite boundary at which the 
spines disappear and the scales begin. The points of the spines are raised at an angle of about $45^{\circ}$ and directed obliquely away from the edge of the wing. Fig. 2, is taken from the edge of the patch on the left wing of Fig. I, and shows both the spines and bordering scales in their relative size and position in relation to the wing. Fig. 3 is a lateral view of the spines as seen from the edge of a fold through the spiny area.

On the thorax the area is of similar form and size, with clearly defined boundaries and is located on the metascutum at the base of the abruptly raised meso-scutellum. See Fig. I, $\mathrm{S}_{1}$, and Fig. $4, S_{1}$. The area on the thorax is slightly raised and flattened and has no scales. The spines which cover this area are precisely like those on the wing and are so directed as to point opposite or nearly opposite to them when the wings are closed. The spiny area when present occurs in both sexes, even on the thorax of the apterous females of the species of Orgyia. In the microlepidoptera, so far as has been observed, the spines both on the wing and thorax are much farther apart than in the Macros.

So far as is known the Rhopalocera do not possess these structures. There is, however, on the fore wings of butterflies a patch of modified scales which are pointed and elevated, but the patch is of irregular shape and has no definite boundary. In some it is very apparent (Anosia plexippus Linn.) while in others it is obscure (Pieris rapae
Linn.). The scales are often smaller than the general type of scales of the wing, but they are much larger than the spines of the Heterocera. There is no corresponding area on the thorax but on the hind wing the scales near the base of the costa are similarly modified. Fig. 5 shows one of the modified scales from $A$. plexippus and Fig. a normal scale from the same wing. Figs. 7 and 8 are respectively the same from Heodes hypophlaeas (Bdv.)

In $A$. plexippus the modified scales are so directed that those on one wing cross those on the other at an angle. If the two detached wings be held in their natural relative positions the scales of the two areas perceptibly interlock. It is possible that these scales assist the wings in making a uniform movement.

It is an interesting fact that some, at least, of the Trichoptera possess similar spiny structures. They are not, however, so well marked as in the Heterocera and in some cases (Leptocerus sp.) they are very indistinct or absent. Neuronia stygipes Hag. and Neuronia semifasciata Say have them well developed, both on the wings and thorax. The most important difference is that in the Trichoptera the spines gradually change to the ordinary slender spines, which cover the whole remaining surface of the wings and body. Fig. 8, shows the location of the patch on the wing of Neuronia and Fig. 1o, shows the spines enlarged. Owing to a lack of duplicate material in this order, only a few species have been examined.

In the Hymenoptera, I have found 
the spiny areas in two species. Tremex columba (Linn.), and Urocerus cressoni Norton, both of which have them very well developed both on the wings and thorax. The patch on the wings bears a close resemblance to that of the Heterocera except that the spines are more blunt. The patch on the thorax can be seen with the naked eye. See Fig. I I, s, and Fig. I2.

The question at once arises for what use are these organs? The theory of Donitz that they are for sexual attraction seems hardly tenable. In this case they must necessarily produce a sound, for they could attract in no other way. This seems scarcely possible, however, when we consider the relative directions in which the spines of the two areas point when they are in contact. In all cases the spines of the two areas point in opposite, or nearly opposite directions, and an attempt to rasp one surface over the other would result in an interlocking of the two as of the teeth of two hostler's grooming cards, whose handles are pointed in opposite directions. The fact that the structures are found in both sexes would also seriously weaken the theory that they are for sexual attraction. The most feasible theory in my opinion is, that they serve to hold the wings in place when at rest, thus allowing a relaxation of the muscles of the wings. We can conceive how this might be a great convenience to moths which close the wings over the back. Of course, the organs would be of no use to moths which do not close their wings in this way, as the Geometrina and Pterophoridae, and these do not have them.
It should be stated, however, that they are not found in all moths which do close the wings; the Sphingidae lack them.

The following is the result of an extended search through the Heterocera for these organs. The families are mentioned in the order in which they occur in Smith's List. It will be found that while the majority of moths have the spiny area, some groups, some parts of groups and some individuals lack them. Families not mentioned have not been examined. As previously stated they are not found in the Sphingidae, although they were discovered in every species which was examined of the Sesiidae. The Agaristidae, Synttomidae, Pyromorphidae, Ctenuchidae, Nycteolidae and Lithosiidae all possess them. Euphanessa mendica Walk., formerly classed with the Lithosiidae lacks them; but this species is now considered by some, at least, to belong to the Geometrina. The Arctiidae, Liparidae, Limacodidae have them and the Notodontidae also with the exception of Apatelodes torrefacta S. \& A. The Platypterygidae and Saturniidae lack them. Of the Ceratocampidae, Eacles imperialis (Dru.) and Dryocampa rubicunda (Fabr.) lack them, while Anisota senatoria S. \& A. has them. The Bombycidae, Cossidae, Hepialidae and all the families of the Noctuina, except the Brephidae have them. As already stated they are not found in the Geometrina.* They

\footnotetext{
* The fact that the spiny area does not occur in Brephos infans Moesch., one of the Brephidae, tends to confirm the statement of Meyrick that "Brephos is a true member of this group," (Geometrina).
} 


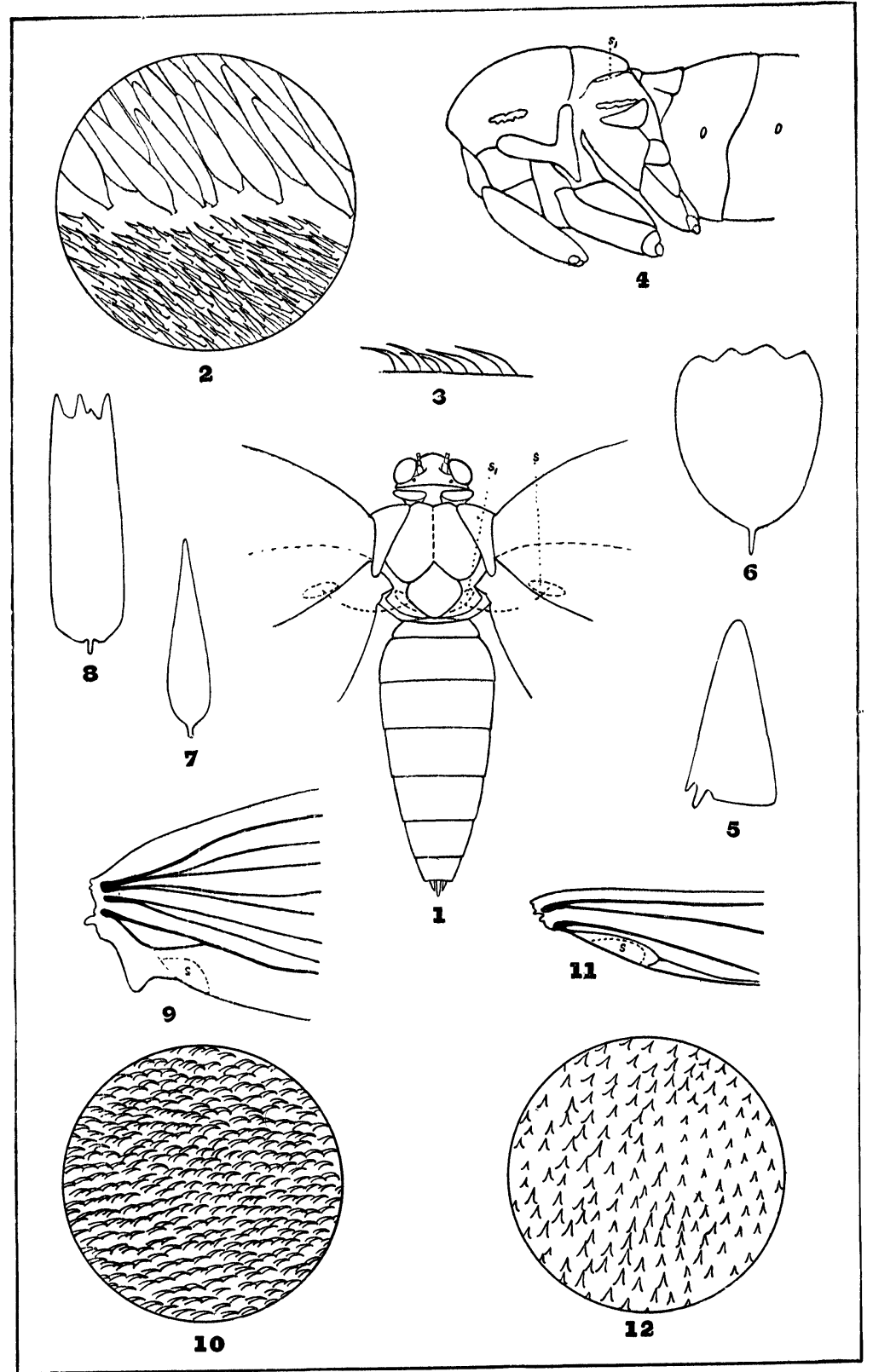

COOLEY, - A NEW STRUCTURAL CHARACTER. 
occur in the Pyraustidae, Pyralididae, Phycitidae and Crambidae. The Pterophoridae do not have them. They are found in the Tortricidae, Grapholithidae, Tineidae, Plutellidae, Gelechiidae, Coleophoridae, Lithocolletidae, Lyonetiidae, Nepticulidae and Micropterygidae.

While it is possible that these spiny areas will not prove of great value in classification, it is somewhat suggestive when a species as Apatelodes torrefacta S. \& A. lacks them; while they are present in genera placed on each side. In such cases they may perhaps aid the systematist.

The following lists contain an enumeration of the insects which I have examined for the spiny area, referred to their families. Numerals indicate the number of species examined.

Species in which the spiny areas are found.

\section{Sesiidae 2}

Agaristidae 5

Syntomidae I

Pyromorphidae 2

Ctenuchidae 3

Nycteolidae I

Lithosiidae ro

Arctiidae 22

Liparidae 3

Limacodidae 7

Notodontidae 23

Ceratocampidae I

Bombycidae 4

Cossidae I

Hepialidae 2

Species in which the spiny areas are absent.

Sphingidae 2 I

Lithosiidae I

Notodontidae I
Thyatiridae 3

Noctuidae 329

Pyraustidae I I

Pyralidae 5

Phycitidae 5

Crambidae I

Tortricidae 17

Grapholithidae I7

Tineidae I

Plutellidae I

Gelechiidae I

Coleophoridae 2

Lithocolletidae I

Micropterygidae I
Platypterygidae 4

EXPLANATION OF PLATE 9 .

Fig. I. Dorsal view of denuded body of Catocala concumbens Walk., showing the spiny area on the wing at $s$, and the corresponding area on the thorax at $S_{1}$.

Fig. 2. Portion enlarged from edge of the spiny area on wing of $C$. concumbens.

Fig. 3. Side view of the spines as seen from the edge of a fold through the spiny area on fore wing of $C$. concumbens.

Fig. 4. Lateral view of denuded body of C. concumbens showing the spiny area at $\mathrm{S}_{1}$.

Fig. 5. Modified scale from the under side of the humeral angle of the fore wing of Anosia plexippus (Linn.)

Fig. 6. Normal scale from near the middle of the under surface of the fore wing of A. plexippus.

Fig. 7. Modified scale from the under side of the humeral angle of the fore wing of Heodes hypophlaeas ( $\mathrm{Bdv}$.)

Fig. 8. Normal scale from near the middle of the under side of the fore wing of $H$. hypophlaeas.

Fig. 9. Basal portion of the fore wing of Neuronia semifasciata Say, showing the spiny area at $\mathrm{s}$.

Fig. 10. Spines from fore wing of $N$. semifasciata enlarged.

Fig. II. Basal portion of fore wing of Tremex columba (Linn.), showing spiny area at s.

Fig. 12. Spines from fore wing of $T$. columba enlarged.

Notes on Butterflies. - I have seen $V$. antiopa lay eggs on white birch and "canoe". birch this year, and as far as I know this is a new food plant for the species.

Papilio turnus is unusually abundant in Brookline, Mass., this year, as well as at Jaffrey, N. H., especially around ash-trees, where I have seen many eggs laid in the past few days, and almost without exception on the higher branches of young trees.

Caroline G. Soule. 

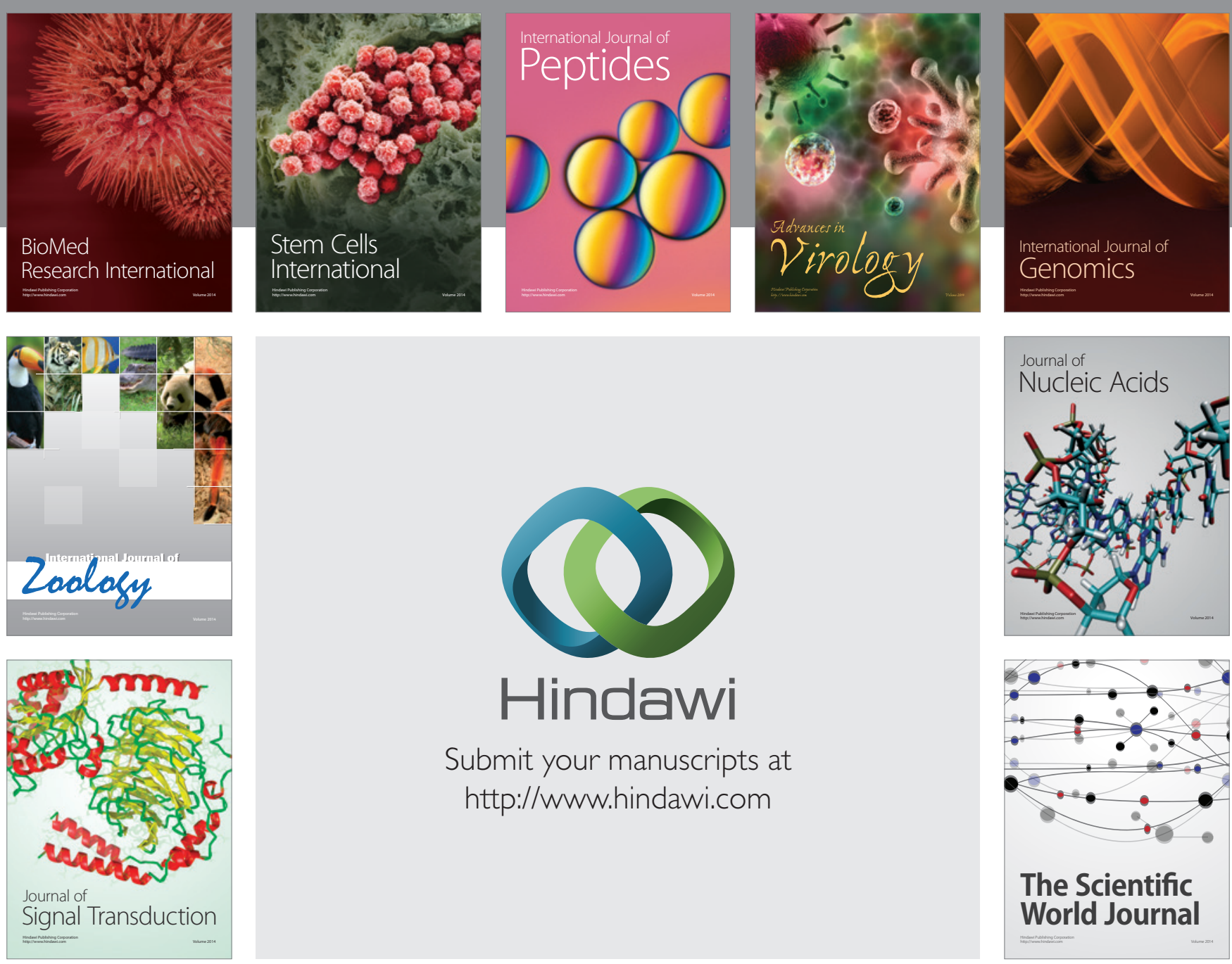

Submit your manuscripts at

http://www.hindawi.com
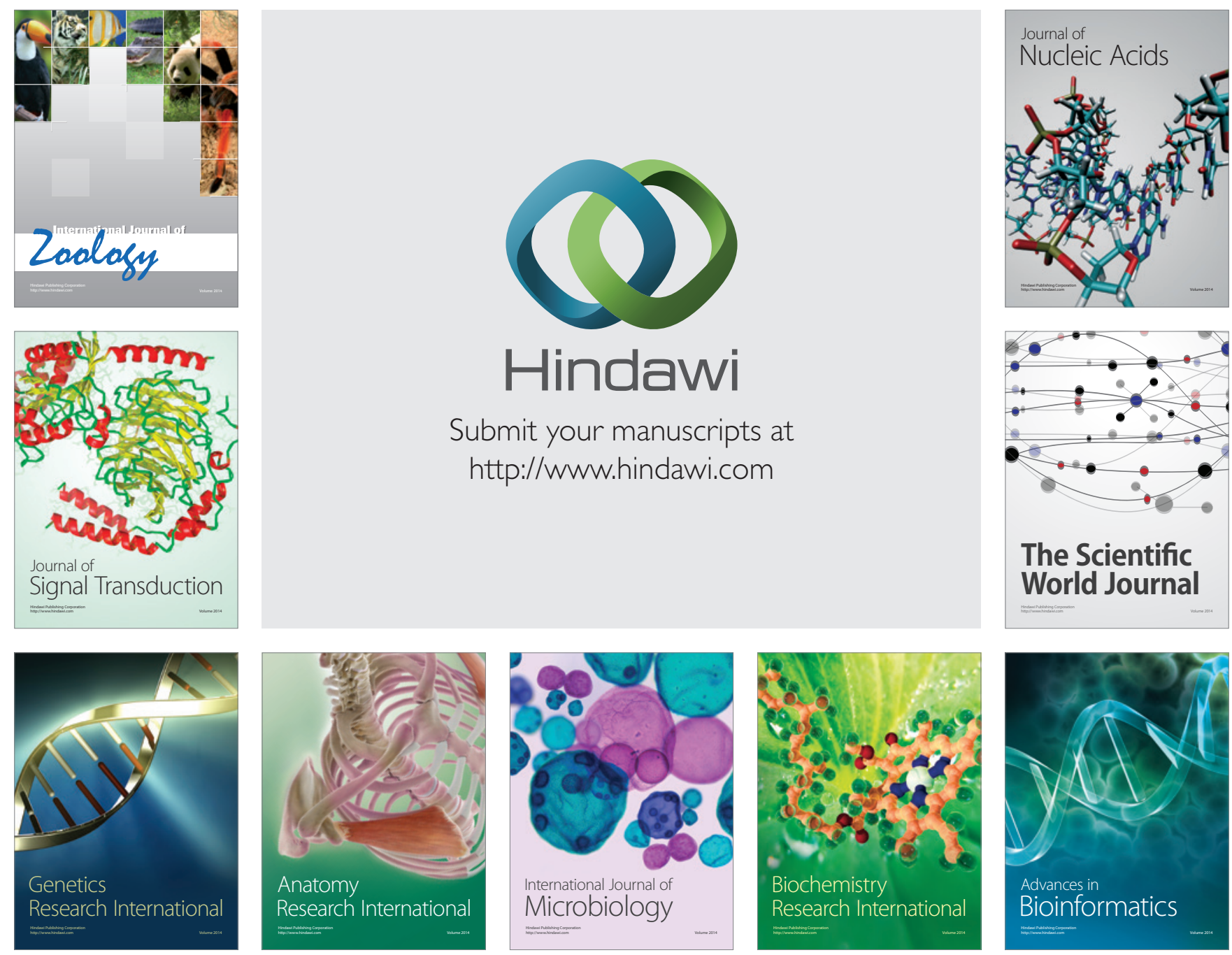

The Scientific World Journal
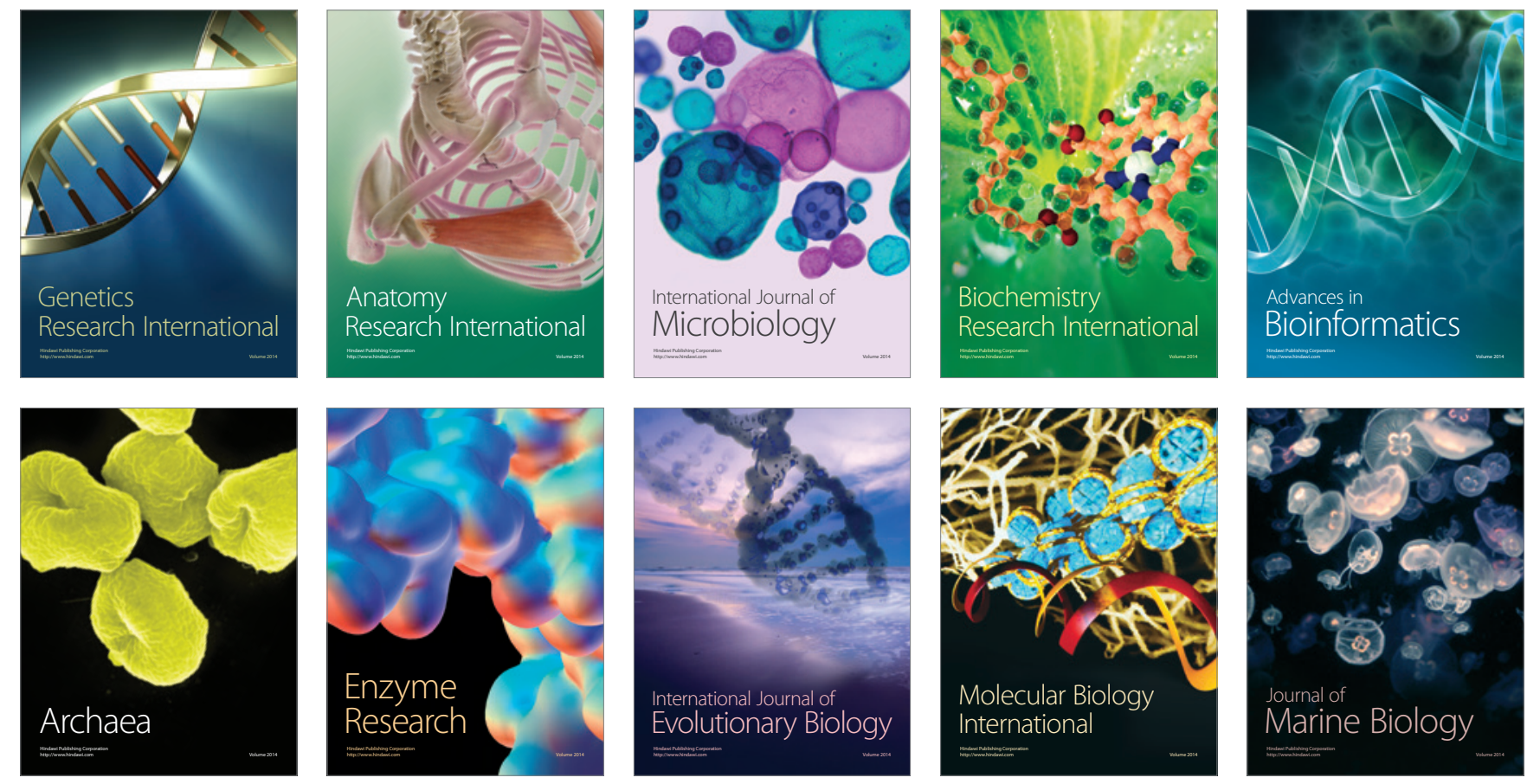